\title{
Pulmonary alveolar proteinosis in children
}

Pulmonary alveolar proteinosis (PAP) is an umbrella term for a wide spectrum of conditions that have a very characteristic appearance on computed tomography. There is outlining of the secondary pulmonary lobules on the background of ground-glass shadowing and pathologically, filling of the alveolar spaces with normal or abnormal surfactant. PAP is rare and the common causes in children are very different from those seen in adults; autoimmune PAP is rare and macrophage blockade not described in children. There are many genetic causes of PAP, the best known of which are mutations in the genes encoding surfactant protein (SP)-B, SP-C, thyroid transcription factor 1, ATP-binding cassette protein 3 , and the granulocyte-macrophage colony-stimulating factor (GM-CSF) receptor $\alpha$ - and $\beta$ - chains. PAP may also be a manifestation of rheumatological and metabolic disease, congenital immunodeficiency, and haematological malignancy. Precise diagnosis of the underlying cause is essential in planning treatment, as well as for genetic counselling. The evidence base for treatment is poor. Some forms of PAP respond well to whole-lung lavage, and autoimmune PAP, which is much commoner in adults, responds to inhaled or subcutaneous GM-CSF. Emerging therapies based on studies in murine models of PAP include stem-cell transplantation for GM-CSF receptor mutations.

\section{Educational aims}

- To understand when to suspect that a child has pulmonary alveolar proteinosis (PAP) and how to confirm that this is the cause of the presentation.

- To show that PAP is an umbrella term for conditions characterised by alveolar filling by normal or abnormal surfactant, and that this term is the start, not the end, of the diagnostic journey.

@ERSpublications

Pulmonary alveolar proteinosis is characterised by alveoli filling with proteinaceous material. There are $>100$ underlying causes, some responding to whole-lung lavage and other more specific treatments, so precise diagnosis is essential. http://bit.ly/2TnkOzm
Cite as: Bush A, Pabary R Pulmonary alveolar proteinosis in children. Breathe 2020; 16: 200001. 
- To review the developmental differences in the spectrum of conditions that may cause PAP, and specifically to understand the differences between causes in adults and children.

- To discuss when to treat PAP with whole-lung lavage and/or granulocytemacrophage colony-stimulating factor, and review potential promising new therapies.

Pulmonary alveolar proteinosis (PAP) can present at any age and the likely diagnosis varies across the developmental course; for example, macrophage blockade syndrome due to silicosis or lymphoma, is never seen in children, and autoimmune PAP, although reported in older children [1], is much commoner in adults. This article will focus on paediatric aspects of PAP and will only briefly draw on adult studies to inform therapeutic strategies where such studies in children are lacking.

\section{Definition}

PAP is conventionally classified into two main types, namely congenital and acquired. The acquired form is subdivided into autoimmune and secondary forms related to an underlying disorder. This classification is far from satisfactory in children, in whom the autoimmune form is very rare, and genetic causes predominate, together with cases secondary to congenital and acquired immunodeficiency, in particular.
A proposed classification for children is given in table 1. Both the adult and our proposed paediatric classifications show overlap between categories. PAP is an umbrella term; a syndrome, not a diagnosis. In many cases, PAP is suspected based on a compatible clinical scenario and typical imaging (see later) and histological confirmation is not sought. Determining the child has PAP is the start of a diagnostic journey (see later) towards defining which of $\sim 100$ conditions is the root cause. PAP should be considered in the differential diagnosis of children's interstitial lung disease (chILD) and in systemic diseases for which PAP may be a comorbidity; in the latter case, irrespective of whether the child has respiratory symptoms. It should not be forgotten that homogeneous, periodic acid-Schiff (PAS)-positive material filling alveoli may have different components with different underlying causes. Lipidomic studies have demonstrated differences in the composition of the material filling the alveolar spaces depending on the underlying cause of PAP [2], which likely has implications for different treatment responses,

Table 1 Proposed classification of paediatric PAP

\begin{tabular}{l} 
Category of disease \\
\hline Disorders of surfactant protein metabolism \\
GM-CSF receptor gene mutations \\
Other genetic disorders \\
Metabolic disease \\
Associated with immune deficiency \\
Congenital \\
Acquired
\end{tabular}

Associated with connective tissue disease Miscellaneous

Diseases seen in adults

Exclusively in adults

Mainly in adults

\section{Exemplar conditions}

SFTPB, STFPC, ABCA3 and TTF1 mutations

$\alpha$ - and $\beta$-chain mutations

MARS, STING, COPA and GATA2 mutations

Lysinuric protein intolerance, Niemann-Pick disease

\author{
SCID, ADA deficiency \\ HIV, leukaemia \\ Idiopathic juvenile chronic arthritis \\ Congenital heart disease
}

Macrophage blockade, lymphoma

Autoimmune

GM-CSF: granulocyte-macrophage colony-stimulating factor; STFPB: surfactant protein B; STFPC: surfactant protein C; ABCA3: ATP-binding cassette 3; TTF1: thyroid transcription factor 1; MARS: methionyl transfer RNA synthetase; STING: stimulator of interferon; COPA: non-clathrin-coated vesicular coat protein A; GATA2: GATA-binding protein 2; SCID: severe combined immunodeficiency; ADA: adenosine deaminase. 
including to whole-lung lavage (see later), which is dramatically successful only in some forms of PAP.

\section{Pathology}

The hallmark pathology of PAP is alveolar filling by PAS-positive endogenous surfactant, which may be normal or abnormal. Cholesterol clefts, and sometimes intraalveolar type 2 cells, foamy macrophages and neutrophils, may be seen [3]. Changes in the alveolar wall vary with underlying pathology. There are rare cases reported of variant PAP, characterised by abundant degenerating macrophages, only weak PAS staining of the intra-alveolar material and only scanty lamellar bodies. Imaging and bronchoalveolar lavage (BAL) findings were not typical of classical PAP and whole-lung lavage was not helpful, but the disease was corticosteroid responsive [4]. The underlying endotype could not be determined. In general, exogenous lipoid pneumonia is suspected if PAS material is not seen within macrophages; genetic causes are favoured by staining both within and outside the alveolar macrophages.

\section{Surfactant biology}

Surfactant is a complex mixture of lipids, mainly phosphatidylcholine, and proteins, the latter accounting for $\sim 10 \%$ by weight of surfactant. There are four surfactant proteins (SP-A to -D), of which two (SP-A and SP-D) are members of the collectin family, together with mannose-binding lectin, and are part of the innate immune system. Interestingly, a kindred with interstitial lung disease related to an SP-A mutation, including an infant, has been described [5], so this tidy classification is flawed. However, SP-A and SP-D have no surface tension properties, and will not be considered further in this review. SP-B and SP-C are surface active, and it is this property that contributes importantly to the stabilisation of the alveoli, and prevents the operation of Laplace's law, whereby smaller alveoli would empty into the larger alveoli and the lungs would collapse into a huge bubble.

Surfactant can be a cause of alveolar filling due to overproduction of abnormal surfactant, failure of clearance or both. The most important transcription factor for SP-B and SP-C is thyroid transcription factor 1 (TTF1 or NKX2.1). SP-B and SP-C undergo complex post-transcriptional processing and among an array of pathways, ATP-binding cassette protein 3 (ABCA3) is crucial; thus conventionally, the four SP genes are SP-B (SFTPB), SP-C (SFTPC), TTF1 (which may have extrapulmonary manifestations, namely brain or thyroid disease) and $A B C A 3$ (figure 1). It is speculative but given that phenotypic primary ciliary dyskinesia (PCD) has been described with normal (i.e. no mutations) ciliary structural genes but mutations in ciliary assembly genes [6], that cases of PAP with failure of synthesis of mature $\mathrm{SP}-\mathrm{B}$ or SP-C may be found in the future related to genes coding for enzymes important in posttranslational modification of SP pre-proteins [7, 8].

Surfactant clearance is by two main mechanisms. The most important is by alveolar macrophages, via the granulocyte-macrophage colony-stimulating

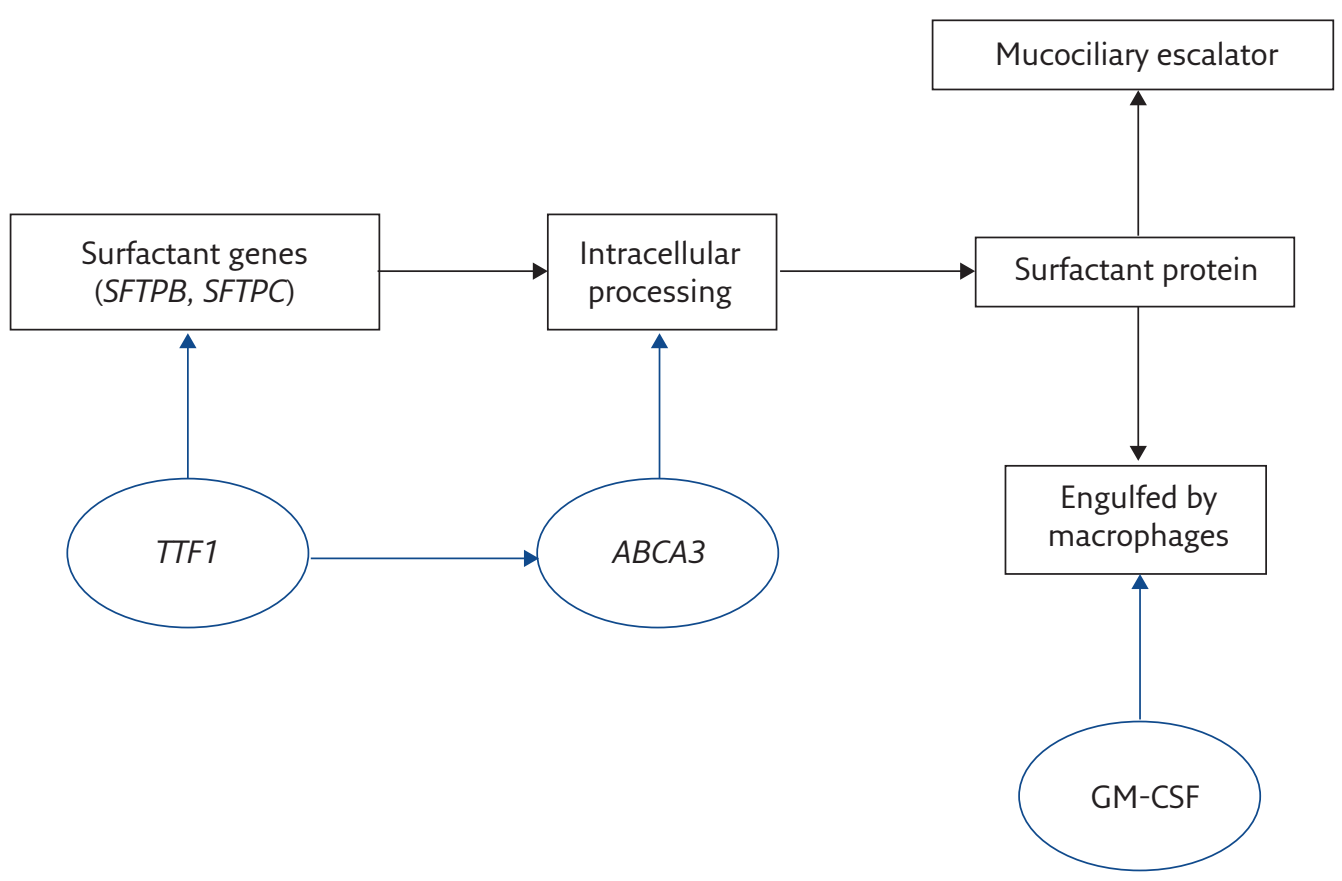

Figure 1 Pathways of surfactant processing. TTF1 is the transcription factor regulating SP-B and SP-C synthesis; $A B C A 3$ is crucial for post-translational, intracellular surfactant processing; granulocyte-macrophage colony-stimulating factor (GM-CSF) regulates surfactant catabolism. The mucociliary escalator is not clinically important in surfactant clearance. 
factor (GM-CSF) receptor. This receptor is a heterodimer of $\alpha$ - and $\beta$ - chains, the $\alpha$-chain (encoded by CSF2RA) being specific for this receptor, the $\beta$-chain (encoded by CSF2RB) also being found in the interleukin (IL)-3 and IL-5 receptors, which signal through JAK/STAT pathways [9]. The second clearance mechanism is the mucociliary escalator. This is of minor importance, since loss of normal mucociliary clearance (MCC) in PCD does not cause PAP and MCC cannot compensate for mutations in the GM-CSF receptor.

\section{Epidemiology}

PAP is a very rare syndrome and there are insufficient good epidemiological data to give an accurate estimate of prevalence. Autoimmune PAP is said to have an incidence of fewer than five in 100000 in Japan [10], which is similar to the prevalence of all causes of chILD [11]. A USA study estimated the overall prevalence at around seven in 1000000 but there were fewer than two in 1000000 under age 18 years [12]. Overall, $>90 \%$ had autoimmune PAP but this is rare in children. Hence, the prevalence of all paediatric PAP is likely well under one in 1000000 and that of the individual aetiologies even lower. Therefore, such children should only be investigated and managed in specialist centres. There is no rigorous evidence base for treatment of children with PAP.

\section{Aetiology}

There are numerous causes of paediatric PAP and they generally cannot be distinguished without performing specific diagnostic tests (see later). They may conveniently be thought of as being due to:

- genetic diseases with no extrapulmonary manifestation (there is some overlap with the next category)

- systemic genetic diseases

- congenital and acquired immunodeficiency

- connective tissue disease

- miscellaneous causes

PAP has been linked with infections, including viral (cytomegalovirus, Epstein-Barr virus and HIV), mycobacterial (Mycobacterium tuberculosis and atypical mycobacteria) and others (Pneumocystis jirovecii and Nocardia) [13], but it is difficult to be sure that the infection was the cause rather than the consequence of PAP itself or the underlying cause of the PAP; and of course, a chest radiograph taken at the time of a coincident intercurrent infection may lead to the diagnosis of PAP.

\section{Disorders of SP metabolism}

It should be noted that alveolar growth disorders are also part of SP mutations and the initial chILD classifications were too rigid; overlaps are commoner than previously thought [14]. Furthermore, SP mutations cause many different histological appearances and these may change over time within an individual [15]. So, for example, PAP may evolve into a more densely fibrotic chILD. SFTPB and $A B C A 3$ mutations are the commonest causes of PAP; SFTPC and TTF1 only rarely present with this histology.

\section{Surfactant protein B}

The 10-kb SFTPB gene is located on chromosome $2 \mathrm{p} 11.2$. Of the 11 exons in the gene, only exons six and seven encode the mature protein. Post-transcriptional modification leads to the production of a 79 amino acid protein. Inheritance is autosomal recessive and the commonest mutation is a frameshift in exon 4, 121ins2, resulting in premature termination of transcription. More than 40 other mutations are described [16] but a mutation cannot be identified in $\sim 30 \%$ cases proven by immunostaining to be SP-B deficient. SP-B mutations are almost invariably fatal in early life unless the baby receives a transplant but a few rare cases with a milder phenotype survive to school age [17].

\section{Surfactant protein C}

The SFTPC gene is a 3.5-kp gene with six exons (exon 2 coding for the mature protein) located on chromosome 8p21.3 [18]. After post-transcriptional processing, a 35 amino acid peptide is produced. More than 40 different mutations have been identified, onethird being p.lle173Thre. The mechanism of disease is gain of function likely leading to endoplasmic reticulum stress; inheritance is autosomal dominant and penetrance is variable, with some presenting with usual interstitial pneumonia in late adult life [19]. A not uncommon paediatric presentation is respiratory syncytial virus bronchiolitis that fails to resolve [20]. Around half of cases are due to de novo mutations.

\section{$\mathrm{ABCA3}$}

The ATP-binding cassette family includes cystic fibrosis transmembrane regulator (CFTR or $A B C A 7$ ). $A B C A 3$ is a large gene, containing 33 exons, and is located on chromosome 16p13.3. Exons 14-17 encode nucleotide-binding domain (NBD) 1 and exons 27-30, NBD2. More than 200 mutations have been reported [21], inheritance is autosomal recessive and age at presentation variable. Patients with two severe mutations (null or loss of function) present early and die or are transplanted within a year of birth [22]. ABCA3 mutations may be the commonest inherited SP abnormality [23].

\section{TTF1}

This small gene (three exons) is located on chromosome $14 q 13.3$ and encodes a transcription 
factor of 371-378 amino acids that controls transcription of multiple genes for proteins expressed in the lung, brain and thyroid, resulting in "brainlung-thyroid syndrome". More than 50 mutations have been described, inheritance is autosomal dominant and penetrance in all three organs affected is variable. About half of the cases arise de novo [24].

\section{GM-CSF receptor mutations}

Typically, GM-CSF receptor mutations do not present in the newborn period, although there are exceptions described [25]. The GM-CSF receptor $\alpha$-subunit is encoded in a gene located in the pseudoautosomal region 1 of the $X$ and $Y$ chromosomes (Xp22.33 and Yp11.2), and the $\beta$-subunit in chromosome 22q12.3. Pulmonary disease in GM-CSF receptor $\alpha$-subunit (CSF2RA) mutations may be silent or symptomatic [26] and, unlike in SP mutations, the interstitial space tends not to be involved. The course of respiratory disease cannot be predicted from the mutation, even between affected siblings. Multiple gene defects are described, including missense, duplication, frameshift and nonsense mutations; exon and gene deletion; and cryptic alternative splicing [27]. It has been suggested that the disease may be precipitated by respiratory infection, including Mycoplasma pneumoniae [28]. There may be poor growth solely as the result of respiratory insufficiency [29]. CSF2RA mutations may also be associated with systemic disease if it is part of a larger deletion in the Xp22.33 region [30]. We have seen two such cases, one associated with short stature and learning difficulties. Extrapulmonary manifestations will depend on which other genes are deleted; in one case, immunodeficiency was a feature [29], emphasising the overlaps in classifications. Other complex combinations of deletions have been described [31]. CSF2RA mutations are also seen in association with Turner's syndrome (46, X0) [32], thus requiring a CSF2RA mutation only on the one $\mathrm{X}$ chromosome. Evidence mainly in CSF2RA mutation disease is that whole-lung lavage (see later) is an effective treatment for GM-CSF receptor mutations and the disease may remit unpredictably after many years of treatment [26]. There is emerging evidence that homozygous (but not heterozygous) mutations in the GM-CSF receptor $\beta$-subunit (CSF2RB) gene can also cause hereditary PAP [27]; in our clinic, a patient with novel homozygous CSF2RB mutations has required whole-lung lavage repeatedly from infancy. Some such patients may have sufficient residual function to benefit from inhaled GM-CSF.

\section{Other genetic disorders causing PAP}

Genetic disorders causing PAP presenting only in adult life (e.g. TERT and SCL34A2) will not be discussed.
Methionyl transfer RNA synthetase

The methionyl transfer RNA synthetase (MARS) gene is a large gene (21 exons) located on chromosome 12q13.3. Only 10 mutations have been described and most cases have been found on La Reunion Island, with the families largely carrying the same mutation [33-36]. The link between the genetic abnormality and PAP is not understood. Onset is most commonly in the first 6 months of life and there is concomitant liver disease progressing to cirrhosis in $20 \%$. Wholelung lavage is, at best, of transient benefit and, despite this therapy, most die of progressive respiratory failure [36].

\section{Stimulator of interferon}

Stimulator of interferon (STING), or transmembrane protein (TMEM)173, plays an important role in innate immunity and is a stimulator of interferon (IFN) genes [37, 38]. It is encoded by TMEM173, located on chromosome 5q31.2. Inheritance may be autosomal dominant with variable penetrance but is usually sporadic; PAP is a rare manifestation and the mechanism is unexplained. The pathophysiology is that gain of function mutations upregulate IFN secretion, and cause autoinflammatory and autoimmune disorders, and SAVI (STING-associated vasculopathy of infancy, also seen in older patients). Importantly, there are specific treatments, tofacitinib and ruxolitinib, both JAK inhibitors, but it is not clear that these are effective in PAP from the small amount of published data [37]. However, a trial of treatment in refractory cases is worth considering.

\section{Non-clathrin-coated vesicular coat protein}

The non-clathrin-coated vesicular coat protein (COPA) gene is located on chromosome 1q23.2; mutations are dominantly inherited with variable disease penetrance [18]. All cases have one of five missense mutations in exons 8-9, encoding the WD40 domain [39]. Lung disease includes fibrosis and haemorrhage, and rarely, PAP; and there may be associated renal disease and arthritis. There is an increased expression of type 1 IFN-stimulated genes. Based on this, there is a report of successful treatment with the specific JAK $1 / 2$ inhibitor ruxolitinib in a child with COPA syndrome and recurrent severe pulmonary haemorrhage [40].

\section{GATA-binding protein 2}

The gene for this zinc finger haematopoietic transcription factor (GATA2) is located on chromosome 3q21.3; inheritance is autosomal dominant [41-43]. Manifestations include haematological malignancies, infections including 
disseminated mycobacterial and invasive fungal disease, skin abnormalities, other neoplastic disease, vascular and lymphatic disease, hypothyroidism, and lung disease, of which PAP comprises 18\%. PAP does not respond to exogenous GM-CSF but improvement with stem cell transplantation has been reported. Despite the profound reduction in circulating monocytes, alveolar macrophage numbers are not affected. PAP is strongly associated with immunodeficiency and myelodysplastic syndrome but the exact pathophysiology could not be determined.

\section{Metabolic disease}

Lysinuric protein intolerance

Solute carrier family 7 member 7 (SLC7A7), the gene causing lysinuric protein intolerance (LPI), is located on chromosome $14 q 1.2$ and inheritance is autosomal recessive. Presentation may be with acute hyperammonaemic coma, or chronically with faltering growth and hypotonia. Complications of this multisystem disease include renal, haematological, bone and gastrointestinal manifestations, but lung disease, present in $\sim 70 \%$ of patients, is the major determinant of prognosis. Initially, lung disease may be asymptomatic. It can occur at any stage of the disease with variable manifestations and clinical course, ranging from acute respiratory failure at presentation to a chronic, indolent trajectory [44, 45]. PAP and fibrosis are the commonest pathologies, and treatment with whole-lung lavage and corticosteroids are ineffective. There is no evidence of involvement of the GM-CSF pathway in pathogenesis and the pathophysiology is unknown. Pulmonary LPI recurs in the transplanted lung [46].

\section{Niemann-Pick disease}

There are three types of Niemann-Pick disease (NPD): NPD-a, NPD-b (most common) and NPD-c; all can be complicated by lung disease [47]. NPD-a and NPD-b are characterised by sphingomyelin accumulation, and NPD-c by defective intracellular trafficking of cholesterol. The prevalence is estimated as one in 150000 . It is a fatal, autosomal recessive disease due. Type $\mathrm{a}$ is due to mutations in SPMD1 (11p15.4) and type $b$ is due to mutations in SMPD2 (6q21). Type $\mathrm{C}$ is due to mutations in one of two genes, NPC1 (18q11.2, 95\%) or NPC2 (14q24.3, 5\%) [48, 49]. There are varying degrees of hepatosplenomegaly, and neurological and pulmonary disease, this last predominantly in NPC2 mutations. Aspiration pneumonia may contribute to the clinical picture. Sea blue histiocytes in BAL may lead to the diagnosis. Miglustat, which may benefit neurological disease, is not useful for pulmonary disease [50], and nor is whole lung lavage [49], but bone marrow transplantation may be helpful [51].

\section{PAP associated with congenital and acquired immunodeficiency}

Numerous immunodeficiencies have been reported to be complicated by PAP, which can also be the first presentation of an immune problem. This underscores the need to make PAP of unknown cause a trigger for immunological review. Congenital immunodeficiencies include agammaglobulinaemia [52], severe combined immunodeficiency secondary to adenosine deaminase deficiency [53], secondary haemophagocytic lymphohistiocytosis [54], infantile hypogammaglobulinaemia with heterozygous OAS1 mutations [55], hyper-IgM syndrome [56, 57], and sporadic and autosomal dominant monocytopenia [58]. Bone marrow or stem cell transplant may be curative for some immunodeficiencies and specialist advice should always be sought [41]. There is a long list of acquired immunodeficiencies complicated by PAP, including HIV (see later) [59].

Leukaemia is the commonest malignancy to be complicated by PAP, albeit rarely. PAP is described in acute lymphoblastic leukaemia, acute and chronic myeloid leukaemia, and myelodysplastic syndromes. This is attributable to chemotherapy- and diseaseinduced macrophage ablation and neutropenia; when the latter reverses and the underlying disease is in remission, in some cases, PAP improves [6062]. Another mechanism is alveolar infiltration by leukaemic blast cells that lack functional GM-CSF signalling due to the absence of either or both the $\alpha$ - and $\beta$-chains [62]. Occurrence after bone marrow transplantation for leukaemia in remission and stem cell transplantation has been described. In one study, there was an apparent increased risk in children with Down syndrome and leukaemia [63]. PAP is an important differential diagnosis of respiratory distress in children with leukaemia; one study [61] suggested a prevalence of $5.3 \%$ in all haematological malignancies and up to $10 \%$ with myeloid diseases, at least in adults. A case report suggests that elevated serum $\mathrm{KL}-6$ is a biomarker for this complication [64] but further confirmatory studies are needed. There may be concomitant infection (e.g. cytomegalovirus) [65]; whether this is a cause or consequence of PAP, or coincidence, is unknown. Whole-lung lavage does not seem to be efficacious in PAP complicating haematological malignancy and supportive treatment while, hopefully, the underlying malignancy goes into remission is the best that can be offered.

\section{Connective tissue disease}

There are numerous pulmonary complications of the connective tissue diseases and their treatment; here, we solely focus on PAP, which is an extremely rare complication with a variable clinical picture in this context. Most data are from the adult literature. Two adults known to have rheumatoid arthritis, one who was being treated with methotrexate, were reported to have autoimmune (GM-CSF 
autoantibody-positive) PAP [66]. There is a single case report of an adult with rheumatoid treated with leflunomide without GM-CSF autoantibodies, which responded to whole-lung lavage and discontinuation of the medication.

There has been increasing recognition of PAP and other chILD, including pulmonary fibrosis in idiopathic juvenile chronic arthritis (SJIA). Two series, together comprising 86 children, highlighted that an ill-defined form of PAP was a feature of this serious complication, which carried a mortality of $>30 \%$ [67-69]. A study of 18 children reported on this poorly characterised lung disease [70]. In most cases, evidence of a major lung disease post-dated the rheumatological diagnosis. The radiology was of ground-glass opacities, subpleural reticulation, interlobular septal thickening and, an atypical feature for PAP, lymphadenopathy. There was no evidence of serum GM-CSF autoantibodies. Those with lung disease tended to have been diagnosed with SJIA earlier, had more episodes of macrophage activation syndrome, more adverse reactions to biologics and higher serum $1 \mathrm{~L}-18$, suggesting a more profound underlying immune dysregulation. Lung biopsy showed patchy but extensive lymphoplasmacytic infiltrates and within the alveolar spaces, a mixed picture of typical PAP and endogenous lipoid pneumonia. Notably, BAL rarely demonstrated proteinaceous material or lipid-laden macrophages, but instead had elevated IL-18 and the IFN- $\gamma$ induced cytokines CXCL9 and CXCL10. Lung tissue transcriptomics suggested upregulation of type II IFN and T-cell activation networks. PAP may also complicate juvenile dermatomyositis [71]. A paediatric rheumatology consultation is advisable if there are any features suggestive of connective tissue disease.

\section{Miscellaneous causes of PAP}

PAP has been described in association with congenital heart disease [72]. Rarely, no cause is found [73].

\section{PAP subtypes seen mainly in adults}

Autoimmune PAP is far commoner in adults but there are a few case reports in children. The disease is caused by IgG autoantibodies to GM-CSF; the underlying cause is unknown and there are no known HLA associations. Treatment is based on adult approaches (see later).

\section{Clinical presentation}

Presentation in the newborn period is with respiratory distress proceeding rapidly to intubation and mechanical ventilation, usually in a term baby, with remorseless deterioration. SP gene mutations should be considered alongside other commoner causes such as congenital infection and aspiration syndromes, and rarer conditions such as alveolar capillary dysplasia with misaligned pulmonary veins and related conditions $[74,75]$. In older children, presentation is more usually with cough, progressive breathlessness and respiratory distress, but first presentation may as a child who has been intubated for type I respiratory failure (carbon dioxide elimination is rarely an issue). In a few children with PAP, particularly with GM-CSF receptor mutations, a more systemic presentation is seen, with fever, weight loss, chest pain and fatigue. In both cases, there may be signs of respiratory distress and increased work of breathing, and digital clubbing. There are usually no auscultatory signs. Evidence of systemic disease, including infections pointing to immunodeficiency, and rheumatological manifestations, should be sought.

\section{Investigations}

These should be considered under two headings:

- investigations to determine whether PAP is the diagnosis

- investigations to determine the underlying specific diagnosis

As with all chILD, the severity of the clinical situation will determine the tempo of investigation.

\section{Is PAP the underlying cause of the symptoms?}

The chest radiograph and pulmonary function tests (if feasible) are nonspecific. The classical high-resolution computed tomography (HRCT) appearances are of (usually diffuse, sometimes patchy) ground-glass shadowing with thickening of the secondary interlobular septa ("cobblestoning"), and if present, should lead to the pursuit of specific underlying causes (figure 2). These may already be known if the context is a child with a known systemic disease (e.g. NPD). Of note, the CT appearances are very specific but PAP may manifest other radiological appearances. In addition to classic cobblestoning, there may be intralobular lines, thickened fissures, micronodules, cystic lesions, consolidation and hyperinflation [76]. These last two are especially found in young children. The distribution is symmetrical, and there is no correlation between clinical and radiological severity. Hence, if clinical suspicion is high, further invasive investigation is mandatory even if CT appearances are atypical, not least because some forms of PAP have specific treatments or genetic implications for the wider family. 

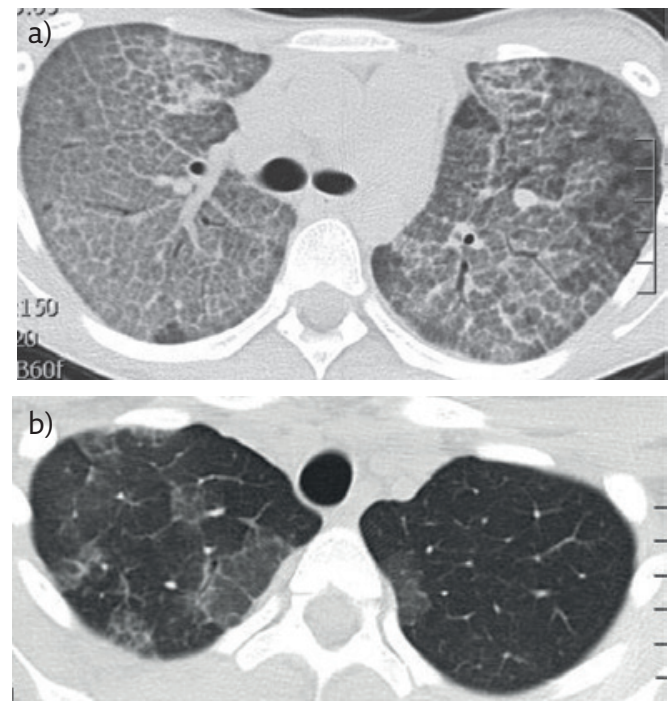

Figure 2 a) Typical computed tomography appearances of PAP in a teenage girl. There is septal thickening outlining the secondary pulmonary lobules on a ground-glass background, giving the typical cobblestoning appearance. The underlying diagnosis was autoimmune PAP. b) Same child after whole-lung lavage (Cliff Morgan, Royal Brompton Hospital, London, UK). There is extensive clearing of the alveolar filling.

Lung function tests are usually only available in older children and are nonspecific. There is usually, but not invariably, restrictive physiology with reduced forced expiratory volume in $1 \mathrm{~s}\left(\mathrm{FEV}_{1}\right)$ and forced vital capacity (FVC) (but normal or high $\mathrm{FEV}_{1}$ /FVC ratio), and low lung volumes and carbon monoxide transfer. Hypoxaemia is present initially on exercise and, later in the course of the disease, also at rest.

A chILD-EU investigation flow chart has been published and emphasises the need to avoid multiple anaesthetics during the diagnostic journey [77]. If the child is stable, the results of at least some genetic tests can be awaited before proceeding to invasive testing. BAL can confirm the diagnosis of PAP and, in some cases, determine the underlying cause. Furthermore, since not all cases of PAP respond to lung lavage (see earlier), a limited $B A L$, specifically whether a milky fluid is returned, may suggest whether attempting therapeutic whole-lung lavage is likely to be beneficial. If an immunodeficiency and an opportunistic infection are suspected, early bronchoscopy is certainly indicated. Otherwise, if the diagnosis is in doubt, a lung biopsy should be performed. The biopsy should be carefully analysed [78] because, for example, electron microscopy of lamellar bodies may point to a diagnosis of specific SP mutations. It is important to distinguish PAP from exogenous and other lipoid pneumonias, for example, due to aspiration of oily laxatives [79]. Finally, as in every respiratory disease that is atypical, consider whether it could be the result of vaping [80], which has been described as causing lipoid pneumonia [81-84].

\section{Investigations to determine the underlying diagnosis}

These will be determined by the overall clinical picture. What is essential is to store DNA for future genetic analyses. First-wave genetic diagnostics in isolated PAP will be for SP and GM-CSF receptor mutations. Depending on the setting, assessment by paediatric immunology, rheumatology and metabolic medicine may be appropriate.

\section{Differential diagnosis}

The differential diagnosis of chILD presenting in the newborn period [74] includes the alveolar capillary dysplasia spectrum and genetic testing, especially for FOXF1 and TBX4, should be performed [75]. The differential diagnosis of later presentations encompasses almost all paediatric respirology, and in particular the other causes of chILD. Pathologically, it is important to differentiate SP-containing lipid, as in PAP, from other causes of alveolar lipid filling. Radiologically, a small study showed that PAP and exogenous lipoid pneumonia could exhibit the classic "crazy paving" appearance, but this was more extensive and severe in PAP $(n=8)$ [85]. Endogenous lipoid pneumonia $(n=6)$ was more often characterised by consolidation and ill-defined centrilobular nodules, the latter not seen in PAP, although the small size of the study militates caution. Rarely, an initial diagnosis of endogenous lipoid pneumonia may precede that of PAP [74].

\section{Complications of PAP}

The major complication is death from respiratory failure due to intractable alveolar filling. Opportunistic infections are a well described complication. There are no purely paediatric large series but a review article summarising data in 75 patients across the developmental spectrum [13] reported that $40 \%$ presented with infection and PAP was the initial diagnosis in only one-third; in the other $27 \%$, the diagnoses were concurrent. PAP was diagnosed only at autopsy in 17 patients. Organisms were Nocardia (43\%), mycobacteria (37\%, both M. tuberculosis and atypical mycobacteria) and fungal (20\%, including Aspergillus species, Histoplasma capsulatum, Cryptococcus and zygomycetes). Nearly one-third also had an extrapulmonary infection. In such series, it is always difficult to tease out whether infection is due to PAP or both are related to underlying immunosuppression, although most in this series were not immunosuppressed. The prognosis was overall poor, with $>50 \%$ dying.

\section{Treatment options}

There are no randomised controlled trials in paediatric PAP. Therapeutic options are determined 
by the underlying aetiology and degree of symptoms, with the goal of improving quality of life. Newer experimental techniques are beginning to focus on treating the underlying defect, for examplem bone marrow transplantation for hereditary PAP [85], with the aim of long-term cure rather than symptom control alone.

\section{Whole-lung lavage}

For most paediatric patients with PAP, the current standard of care is whole-lung lavage, which removes accumulated surfactant through instillation and removal of warmed saline from the lungs [86]. The details are illustrated in figure 3. In older children, the procedure is relatively straightforward as large volumes (up to $40 \mathrm{~L}$ per lung in cyclical aliquots) can be instilled into one lung under general anaesthesia via a double-lumen endotracheal tube that simultaneously allows single-lung ventilation of the contralateral side. As each instilled aliquot of saline is drained by gravity, there is progressive clearing of protein and, after a 60-90-min break, the opposite lung can be lavaged in the same way. In smaller children in whom a double-lumen endotracheal tube cannot be passed (the smallest commercially available size is 26 French), the procedure is more difficult and necessitates use of a bronchial blocker to isolate the lung that is to be lavaged, whilst the contralateral side is ventilated with a conventional endotracheal tube [87]. The volumes that can be instilled in this situation are limited by the small diameter of the airway and the blocker, and, in our centre, we maintain constant bronchoscopic visualisation to ensure that the blocker does not herniate upwards leading to catastrophic filling of the contralateral lung with saline. Experienced anaesthetic support is essential; techniques such as three-dimensional printing of the airway from $\mathrm{CT}$ scans can provide vital information ahead of the procedure about viable ventilation strategies [88]. Due to the technical difficulties, younger children may need sequential lavages to maximise benefit, which may lead to complications such as airway stenosis. We now use a semiautomated technique of instilling and removing saline using a perfusion circuit; this allows pressure to be monitored as the lungs fill, and is less likely to result in movement of the bronchial blocker as manual instillation and removal of saline using syringes is no longer necessary. An alternative approach is to simultaneously lavage both lungs whilst the child is on cardiopulmonary bypass but this has potential for significant complications [89].

Whole-lung lavage improves symptoms and oxygenation in $\sim 95 \%$ of patients with PAP [90] (it is not efficacious in secondary PAP complicating haematological malignancies, for example [91]). Concomitant manual chest percussion during whole-lung lavage may increase therapeutic benefit [92] but there is no consensus for use in children. Complications include hydrothorax, pneumothorax, intraoperative hypoxia, fluid leak into the contralateral lung [88] and, potentially, death. Disease progression is difficult to predict; some children experience prolonged improvement in symptoms following a single procedure whilst others require whole-lung lavage repeated multiple times over many years, with differences in requirement seen even when underlying aetiologies are similar (for example, GM-CSF receptor mutations). Wide disparities in remission rates are reported in the literature $(\leq 10 \%$ to $70 \%)$ and it remains unclear whether patients are truly rendered disease free or if the disease has a waxing and waning pattern of exacerbation and subclinical quiescent disease [93].

There are also reports of whole-lung lavage being ineffective in children with disorders of surfactant production, with some $\mathrm{SP}-\mathrm{C}$ mutations responding better than others. The protein content of lavage fluid in these conditions is lower than in other types of PAP, indicating that respiratory compromise in this group is not solely attributable to alveolar filling [3] and therefore other strategies such as lung transplantation might be required.

\section{Granulocyte-macrophage colony-stimulating factor}

Amelioration of autoimmune PAP by subcutaneous administration of GM-CSF to replace that affected by autoantibodies was first demonstrated in 1996 [94] and subsequently, nebulisation of GM-CSF was shown to have similar efficacy with fewer adverse events [95, 96]. Although rare, there are case reports of autoimmune PAP in the paediatric population treated successfully with whole-lung lavage followed by nebulised GM-CSF [97]; results of an ongoing, international, doubleblind, randomised, placebo-controlled trial of recombinant inhaled GM-CSF in adult patients (molgramostim) are therefore eagerly awaited. Empirical nebulised GM-CSF has historically been used in children even where autoantibodies were not detected [87]; development of the STAT5 phosphorylation index assay, which detects downstream activation of GM-CSF receptor [27], makes it possible to monitor any response to treatment and allows discontinuation of nebulised GM-CSF in nonresponders.

\section{Other therapies for autoimmune PAP}

Other approaches to autoimmune PAP have been to target autoantibodies themselves. In one case report, plasmapheresis performed sequentially over a period of 10 months significantly lowered autoantibody concentration but without symptomatic improvement [97], whilst in another, there was significant benefit after just two plasma 

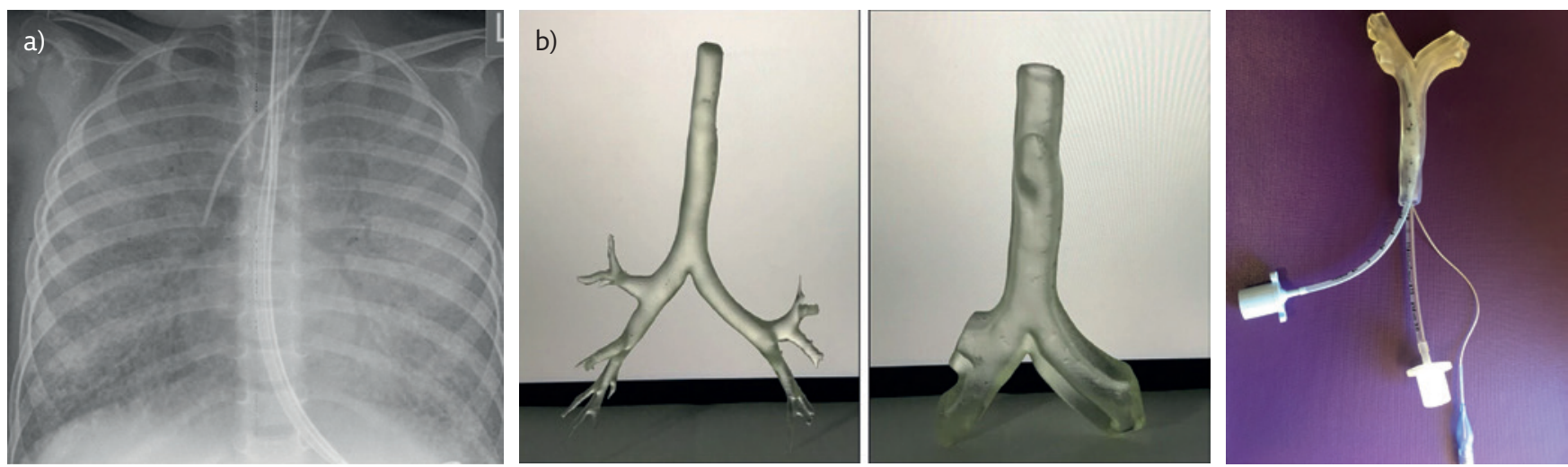

c)
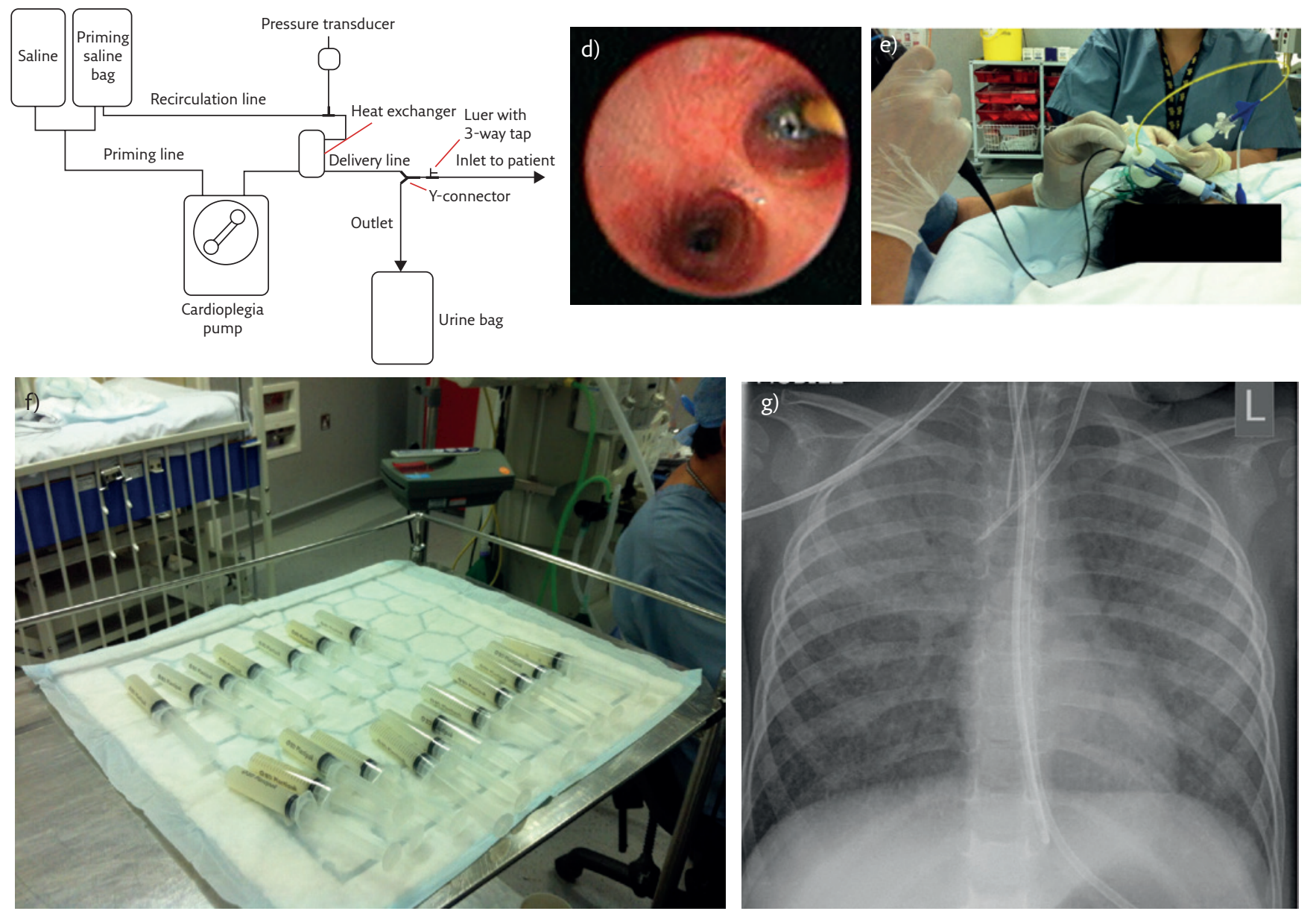

Figure 3 Whole-lung lavage in a 2-year old girl with PAP due to a homozygous CSR2RB mutation. a) Chest radiograph prior to lavage. There is diffuse, bilateral nonspecific shadowing. The appearances are not specific for PAP. b) Three-dimensional model of trachea with two endotracheal tubes in situ. The model, printed from HRCT images, allows pre-procedure planning of ventilation, bronchial blocker and lavage strategy in patients in whom a double-lumen tube cannot be passed. c) Schematic diagram of the semiautomated circuit used for whole-lung lavage in smaller patients. d) Bronchoscopic view of the bronchial blocker in the left main bronchus, prior to instilling lavage fluid into the left lung. e) Whole-lung lavage. The bronchoscopist is carefully checking the position of the bronchial blocker, while a second operator is, in this case, using a syringe to perform the lavage. Note the creamy-coloured fluid in the aspirating syringe, typical of PAP. f) Serial aliquots of lavage fluid. Note that as the lavage has proceeded, the fluid becomes clearer. g) Chest radiograph following right sided lung lavage in the same child as in part a. There is substantial clearing of the changes in the right middle and lower lobes; the right upper lobe could not be lavaged because it was impossible to obtain a stable occlusion position in the right main bronchus and the bronchial blocker was placed in the right bronchus intermedius.

exchanges [98]. A third study reported that combining plasmapheresis over five consecutive days with rituximab resulted in less requirement for whole-lung lavage, and improvement in dyspnoea and diffusing capacity for carbon monoxide [99]. However, in a study of 13 adult patients receiving rituximab alone, no improvement in any subjective or objective endpoints was demonstrated [100]. Also mediating against immunomodulation in autoimmune PAP is the finding that corticosteroids worsen respiratory symptoms, with an increased incidence of infection [101]. At present, none of 
these strategies are considered viable treatment options in children.

\section{Emerging medical therapies: cholesterol metabolism}

A recent case report of a 58-year-old female with autoimmune PAP confirmed by the presence of GM-CSF antibodies and abnormal STAT5 phosphorylation index assay highlighted the potential for statins as a novel therapy for PAP [102]; her symptoms were refractory to treatment with nebulised GM-CSF and multiple wholelung lavages but improved unexpectedly after treatment for coincident hypercholesterolaemia with complete resolution of HRCT changes over a 42-month period. In a validated animal model of PAP (CSF2RB ${ }^{-1-}$ mice), it was demonstrated that statins reduced both $B A L$ turbidity and cholesterol in alveolar macrophages (with increased cholesterol efflux from the macrophage) with a resultant improvement in symptoms [102]. Together, these findings suggest medications targeting cholesterol homeostasis might be beneficial for all types of PAP; we have recently commenced a child with refractory PAP due to a novel homozygous CSF2RB mutation on simvastatin and long-term follow-up is ongoing.

\section{Studying novel treatment options using cell and animal models of PAP}

As with most chILD, rarity means that large randomised controlled trials will likely never be performed, and so we must have recourse to animal and cellular models of disease. Human pluripotent stem cells were created from two children with PAP due to R217X mutations in the GM-CSF receptor $\alpha$-chain and differentiated into macrophages. Stem cells undergoing the same process from three normal people were used as comparators. The PAP macrophages had reduced GM-CSF receptor expression and specific GM-CSFdependent gene expression, which was reversed by in vitro lentiviral mediated gene correction [103, 104]. Another valuable model is a murine $\mathrm{CSFRB}^{-/-}$, which recapitulates the features of human PAP and was used to demonstrate the long-term efficacy of a single intrapulmonary transplantation of differentiated, lineage-negative, bone marrow cells from wild-type mice [105]. These sorts of model systems will undoubtedly be used more extensively to test novel treatments in the future. Gene therapy is also postulated as a treatment for autoimmune PAP; in both a murine model and ex vivo air-liquid interface cultures, transduction using a lentiviral vector carrying GM-CSF cDNA led to reduced BAL turbidity and long-term increases in GM-CSF [106]. Another study demonstrated that instillation of either wildtype or CSF2RB ${ }^{-1-}$ gene-corrected, bone marrowderived macrophages directly into the murine lung

\section{Self-assessment questions}

1. Which of the following statements about the SP genes is true?

a. SP-B and SP-C, but not SP-A and SP-D, are surface active and prevent lung collapse.

b. Mutations in all four SP genes are causes of chILD.

c. There are occasional reports of prolonged survival in babies homozygous for the SP-B 121lns2 mutation.

d. PAP due to SP-C and $A B C A 3$ mutation is dominantly inherited.

e. TTF1 is the largest SP gene causing PAP.

2. Neonatal presentation with severe respiratory distress is very common in which gene mutations?
a. $\mathrm{SP}-\mathrm{C}$
b. $A B C A 3$
c. GM-CSF receptor
d. COPA
e. SLC7A7

3. PAP is not with systemic features in which genetic abnormality?
a. STING mutation
b. TTF1 mutation
c. CSF2RA mutation
d. NPD
e. SP-B mutation

4. Which of the following causes of PAP are more common in children than adults>
a. Macrophage blockade
b. Autoimmune PAP
c. TERT mutations
d. SCL34A2 mutations
e. Hyper-lgM syndrome

5. Which statements are false in whole-lung lavage performed for PAP?

a. It is not helpful in PAP complicating haematological malignancies.

b. It may need repeating in CSF2RA mutations but such patients may remit spontaneously.

c. It can be combined with inhaled GM-CSF therapy in autoimmune PAP.

d. It is most conveniently performed on extracorporeal membrane oxygenation (ECMO) in pre-school children.

e. No more than $4 \mathrm{~L}$ lavage can be used for whole-lung lavage at any one anaesthetic.

6. Which of the following statements are true with regards to the pathophysiology of PAP?

a. A positive PAS stain is specific and pathognomonic for PAP.

b. The mucociliary escalator plays a significant role in surfactant clearance.

c. Heterozygous mutations in CSF2RB are a cause of hereditary PAP.

d. GM-CSF mediates macrophage maturation by binding to the GM-CSF receptor and thereby facilitates surfactant degradation.

e. Toxins and dust exposure are a common cause of secondary PAP in children.

corrected lung disease, with persistence of the functioning macrophages in BAL for $\geq 12$ months after a single administration [107]. As there is no requirement for myeloablation and treatment could 


\section{Suggested answers}

1. a. SP-D is not a cause of chILD; long-term survival is not reported in 121 Ins 2 but in milder mutations; SP-C is an autosomal dominant and $A B C A 3$ recessive; TTF1 is the smallest gene and $A B C A 3$ the largest.

2. $\mathrm{a}$ and $\mathrm{b}$. SP-C and $A B C A 3$ gene mutations are well described as presenting in the newborn period (although both can present at any age) but typically the other gene mutations present outside the newborn period, in infancy or later.

3. e. SP-B. PAP in STING mutation and NPD is part of the systemic disease; TTF1 may be associated with brain and thyroid disease; extrapulmonary disease has been described in association with CSF2RA if it is part of a chromosomal deletion.

4. e. All the other causes are commoner in adults (b) or not described in children (a, c and d).

5. $d$ and e. Although whole-lung lavage can be performed on ECMO, this is a much more major procedure than performing it bronchoscopically; up to $40 \mathrm{~L}$ saline can be used in teenagers undergoing whole-lung lavage.

6. d. A positive PAS stain of transbronchial biopsies or BAL is a hallmark of PAP but is not specific to this alone, and can also be seen in other conditions, for example in liver biopsies of patients with glycogen storage diseases. Mucociliary clearance does not have a major role in surfactant clearance; the main mechanism is via alveolar macrophages. Only homozygous mutations in CSF2RB have been described as a cause of hereditary PAP. GM-CSF is needed to mediate maturation of alveolar macrophages, which can then degrade surfactant; when this does not happen, if there are autoantibodies or GM-CSF receptor mutations, for example, surfactant accumulation occurs. Toxin and dust exposure is a relatively common cause of secondary PAP in adults but is rarely described in children.

be delivered locally via a bronchoscope, this approach is perhaps the most attractive emerging strategy for children with hereditary PAP.

\section{Transplantation}

Lung transplantation has been undertaken in adult patients with hereditary PAP but recurrence has been reported, with replacement of donor alveolar macrophages with recipient macrophages [108], suggesting that renewal of alveolar macrophages involves precursor cells derived from the bone marrow. Thus, for PAP due to GM-CSF receptor mutations, bone marrow transplantation is an emerging option with bone marrow reconstitution from a healthy donor giving rise to healthy alveolar macrophages that express GM-CSF receptor, thereby restoring surfactant metabolism. Originally demonstrated in the CSF2RB-/- murine model [109], this has recently been successful in a child, although there were complications including severe graft versus host disease (GVHD) and obliterative bronchiolitis [88], which indicate it is not an approach to be undertaken lightly. An alternative is haematopoietic stem cell transfer, which requires myeloablation but obviates the need for post-transplant immunosuppression and avoids GVHD [110].

\section{Other considerations}

Whether infection precedes PAP or PAP predisposes to infection remains unclear; prophylactic use of antibiotics such as azithromycin should be considered as even common respiratory infections may worsen symptoms in children with PAP. Other therapies used in chILD, such as hydroxychloroquine and methotrexate, are not thought to be efficacious. Unexpected clinical improvement has been demonstrated in a neonate with congenital PAP of unknown aetiology who was administered intravenous immunoglobulin (IVIG) for infection prophylaxis [111], raising the possibility that IVIG be considered if conventional therapy is ineffective, or of course if immunodeficiency is the underlying cause of PAP. Another paediatric case reports successful use of antiviral therapy in conjunction with whole-lung lavage in a child with PAP secondary to Epstein-Barr virus infection [112]. If despite whole-lung lavage, there is a residual oxygen requirement, nocturnal noninvasive ventilation may be indicated. Finally, although not reported in the paediatric literature, PAP induced by allergens is relatively common in adults [10] so possible exposures should be considered and minimised if thought to be contributory.

\section{Conclusions}

The syndrome PAP can be caused by numerous pulmonary and systemic, congenital and acquired diseases. It is important to have a high index of suspicion and pursue the underlying diagnosis aggressively, because there are very specific treatments for an increasing number of these patients. A systematic approach to elucidating the underlying diagnosis is essential. In the future, novel therapies are likely to be studied in the validated murine models.

\section{Key points}

- PAP is a description not a diagnosis, and should prompt detailed evaluation to determine the underlying cause.

- The spectrum of causes of PAP is very different in childhood compared with adults; causes include multiple different genetic syndromes, 
underlying immunodeficiency and haematological malignancy, and rheumatological syndromes.

- Precise delineation of the underlying diagnosis is essential in planning treatment and for genetic counselling of the family.

\section{Affiliations}

\section{Andrew Bush ${ }^{1,2}$, Rishi Pabary ${ }^{1,2}$}

${ }^{1}$ Imperial College, London, UK. ${ }^{2}$ Royal Brompton Harefield NHS Foundation Trust, London, UK.

\section{Conflict of interest}

None declared.

\section{References}

1. Price A, Manson D, Cutz E, et al. Pulmonary alveolar proteinosis associated with anti-GM-CSF antibodies in a child: successful treatment with inhaled GM-CSF. Pediatr Pulmonol 2006; 41: 367-370.

2. Griese M, Bonella F, Cosyabel U, et al. Quantitative lipidomics in pulmonary alveolar proteinosis. Am J Respir Crit Care Med 2019; 200: 881-887.

3. Griese M. Pulmonary alveolar proteinosis: a comprehensive clinical perspective. Pediatrics 2017; 140: e20170610.

4. Nishino M, Medoff BD, Mark EJ, et al. Variant alveolar lipoproteinosis: a syndrome with distinct clinical and pathological features. Pathol Int 2011; 61: 509-517.

5. Nathan N, Giraud V, Picard C, et al. Germline SFTPA1 mutation in familial idiopathic interstitial pneumonia and lung cancer. Hum Mol Genet 2016; 25: 1457-1467.

6. Olcese C, Patel MP, Shoemark A, et al. X-linked primary ciliary dyskinesia due to mutations in the cytoplasmic axonemal dynein assembly factor PIH1D3. Nat Commun 2017; 8: 14279.

7. Johnson AL, Braidotti P, Pietra GG, et al. Post-translational processing of surfactant protein- $\mathrm{C}$ proprotein: targeting motifs in the $\mathrm{NH}_{2}$-terminal flanking domain are cleaved in late compartments. Am J Respir Cell Mol Biol 2001; 24: 253-263.

8. Beers MF, Hamvas A, Moxley MA, et al. Pulmonary surfactant metabolism in infants lacking surfactant protein B. Am J Respir Cell Mol Biol 2000; 22: 380-391.

9. Hansen G, Hercus TR, McClure BJ, et al. The structure of the GM-CSF receptor complex reveals a distinct mode of cytokine receptor activation. Cell 2008; 134: 496-507.

10. Inoue Y, Trapnell BC, Tazawara R, et al. Characteristics of a large cohort of patients with autoimmune pulmonary alveolar proteinosis in Japan. Am J Respir Crit Care Med 2008; 177: 752-762.

11. Hime NJ, Zurynski Y, Fitzgerald D, et al. Childhood interstitial lung disease: a systematic review. Pediatr Pulmonol 2015 50: 1383-1392.

12. McCarthy C, Avetisyan R, Carey BC, et al. Prevalence and healthcare burden of pulmonary alveolar proteinosis. Orphanet J Rare Dis 2018; 13: 129.

13. Punatar AD, Kusne S, BlairJE, et al. Opportunistic infections in patients with pulmonary alveolar proteinosis. I Infect 2012; 65: 173-179.

14. Rice A, Tran-Dang MA, Bush A, et al. Diffuse lung disease in infancy and childhood: expanding the chILD classification. Histopathology 2013; 63: 743-755.

15. Doan ML, Guillerman RP, Dishop $M K$, et al. Clinical, radiological and pathological features of $A B C A 3$ mutations in children. Thorax 2008; 63: 366-373.
16. Nathan N, Taam RA, Epaud R, et al. A national internet-linked based database for pediatric interstitial lung diseases: the French network. Orphanet J Rare Dis 2012; 7: 40.

17. Dunbar AE 3rd, Wert SE, Ikegami $M$, et al. Prolonged survival in hereditary surfactant protein B (SP-B) deficiency associated with a novel splicing mutation. Pediatr Res 2000; 48: 275-282.

18. Nathan N, Borensztajn K, Clement A. Genetic causes and clinical management of pediatric interstitial lung diseases. Curr Opin Pulm Med 2018; 24: 253-259.

19. Thomas AQ, Lane K, Phillips J 3rd, et al. Heterozygosity for a surfactant protein $C$ gene mutation associated with usual interstitial pneumonitis and cellular nonspecific interstitial pneumonitis in one kindred. Am J Respir Crit Care Med 2002; 165: 1322-1328.

20. Thouvenin G, Abou Taam R, Flamein F, et al. Characteristics of disorders associated with genetic mutations of surfactant protein C. Arch Dis Child 2010; 95: 449-454.

21. Kroner C, Wittman T, Reu S, et al. Lung disease caused by ABCA3 mutations. Thorax 2017; 72: 213-220.

22. Wambach JA, Casey AM, Fishman MP, et al. Genotypephenotype correlations for infants and children with ABCA3 deficiency. Am J Respir Crit Care Med 2014; 189: 1538-1543.

23. Zhou W, Zhuang $Y$, Sun J, et al. Variants of the $A B C A 3$ gene might contribute to susceptibility to interstitial lung diseases in the Chinese population. Sci Rep 2017; 7: 4097.

24. Nattes E, Lejeune S, Carsin A, et al. Heterogeneity of lung disease associated with NK2 homeobox 1 mutations. Respir Med 2017; 129: 16-23.

25. Dirksen U, Nishinakamura R, Groneck P, et al. Human pulmonary alveolar proteinosis associated with a defect in GM-CSF/IL-3/IL-5 receptor common beta chain expression. J Clin Invest 1997; 100: 2211-2217.

26. Hildebrandt J, Yalcin E, Bresser HG, et al. Characterization of CSF2RA mutation related juvenile pulmonary alveolar proteinosis. Orphanet J Rare Dis 2014; 9: 171.

27. Suzuki T, Maranda B, Sakagami T, et al. Hereditary pulmonary alveolar proteinosis caused by recessive CSF2RB mutations. Eur Respir J 2011; 37: 201-204.

28. Santiago-Burruchaga M, Zalacain-Jorge R, Alvarez-Martinez J, et al. Hereditary pulmonary alveolar proteinosis. Could it be triggered by Mycoplasma pneumoniae pneumonia? Respir Med 2013; 107: 134-138.

29. Suzuki T, Sakagami T, Rubin BK, et al. Familial pulmonary alveolar proteinosis caused by mutations in CSF2RA.J Exp Med 2008; 205: 2703-2710.

30. Chiu CY, Su SC, Fan WL, et al. Whole-genome sequencing of a family with hereditary pulmonary alveolar proteinosis identifies 
a rare structural variant involving CSF2RA/CRLF2/IL3RA gene disruption. Sci Rep 2017; 7: 43469

31. Auger J, Bonnet C, Valduga $M$, et al. De novo complex $X$ chromosome rearrangement unmasking maternally inherited CSF2RA deletion in a girl with pulmonary alveolar proteinosis. Am J Med Genet A 2013; 161A: 2594-2599.

32. Martinez-Moczygemba M, Doan ML, Elidemir O, et al. Pulmonary alveolar proteinosis caused by deletion of the $\mathrm{GM}-\mathrm{CSFR} \alpha$ gene in the $\mathrm{X}$ chromosome pseudoautosomal region 1. J Exp Med 2008; 205: 2711-2716.

33. Enaud L, Hadchouef A, Coulomb A, et al. Pulmonary alveolar proteinosis in children on La Reunion island: a new inherited disorder? Orphanet J Rare Diseases 2014; 9: 85.

34. Alzaid M, Alshamrani A, Al Harbi AS, et al. Methionyl-tRNA synthetase novel mutation causes pulmonary alveolar proteinosis. Saudi Med J 2019; 40: 195-198.

35. Abuduxikuer K, Feng JY, Lu Y, et al. Novel methionyl-tRNA synthetase gene variants/phenotypes in interstitial lung and liver disease: A case report and review of literature. World Gastroenterol 2018; 24: 4208-4216.

36. Hadchouel A, Wieland T, Griese M, et al. Biallelic mutations of methionyl-tRNA synthetase cause a specific type of pulmonary alveolar proteinosis prevalent on Réunion Island. AmJ Hum Genet 2015; 96: 826-831.

37. de Jesus AA, Hou Y, Brooks S, et al. Distinct interferon signatures and cytokine patterns define additional systemic autoinflammatory diseases. J Clin Invest 2020; 130 : 1669-1682.

38. Liu Y, Jesus AA, Marrero B, et al. Activated STING in a vascular and pulmonary syndrome. N Engl J Med 2014; 371: 507-518.

39. Watkin LB, Jessen B, Wisniewski W, et al. Copa mutations impair ER-Golgi transport and cause hereditary autoimmune mediated lung disease and arthritis. Nat Genet 2015; 47 : 654-660.

40. Fremond $M-L$, Legendre $M$, Fayon $M$, et al. Use of ruxoliitinib in COPA syndrome manifesting as life-threatening alveolar haemorrhage. Thorax 2020; 75: 92-95.

41. Tanaka-Kubota M, Shinozaki K, Miyamoto S, et al. Hematopoietic stem cell transplantation for pulmonary alveolar proteinosis associated with primary immunodeficiency disease. Int J Hematol 2018; 107: 610-614.

42. Griese M, Zarbock R, Costabel U, et al. GATA2 deficiency in children and adults with severe pulmonary alveolar proteinosis and hematologic disorders. BMC Pulm Med 2015; 15: 87.

43. Spinner MA, Sanchez LA, Hsu AP, et al. GATA2 deficiency: a protean disorder of hematopoiesis, lymphatics, and immunity. Blood 2014; 123: 809-821.

44. Valimahamed-Mitha S, Berteloot L, Ducoin $\mathrm{H}$, et al. Lung involvement in children with lysinuric protein intolerance. $J$ Inherit Metab Dis 2015; 38: 257-263.

45. Habarou F W, Gobin S, Servais A, et al. Update on Lysinuric Protein Intolerance, a Multi-faceted Disease Retrospective cohort analysis from birth to adulthood. Orphanet J Rare Dis 2017; 12: 3 .

46. Santamaria F, Brancaccio G, Parenti G, et al. Recurrent fatal pulmonary alveolar proteinosis after heart-lung transplantation in a child with lysinuric protein intolerance. J Pediatr 2004; 145: 268-272.

47. Von Ranke FM, Freitas HMP, Mancano AD, et al. Pulmonary involvement in Niemann-Pick disease: a state-of-the-art review. Lung 2016; 194: 511-518.

48. Sheth J, Joseph JJ, Shah K, et al. Pulmonary manifestations in Niemann-Pick type $\mathrm{C}$ disease with mutations in NPC2 gene: case report and review of literature. BMC Med Genet 2017; 18: 5

49. Bjurulf B, Spetalen S, Erichsen A, et al. Niemann-Pick disease type C2 presenting as fatal pulmonary alveolar lipoproteinosis: morphological findings in lung and nervous tissue. Med Sci Monit 2008; 14: CS71-CS75.

50. Pineda M, Wraith JE, Mengel E, et al. Miglustat in patients with Niemann-Pick disease Type C (NP-C): a multicentre observational retrospective cohort study. Mol Genet Metab 2009; 98: 243-249.
51. Bonney DK, O'Meara A, Shabani A, et al. Succesful allogenic bone marrow transplant for Miemann-Pick disease type C2 is likely to be associated with a severe 'graft versus substrate' effect. J Inherit Metab Dis 2010; 33: Suppl. 3, S171-S173.

52. Patiroglu T, Akyildiz B, Patiroglu TE, et al. Recurrent pulmonary alveolar proteinosis secondary to agammaglobulinemia. Pediatr Pulmonol 20081; 43: 710-713.

53. Grunebaum E, Cutz E, Roifman CM. Pulmonary alveolar proteinosis in patients with adenosine deaminase deficiency. J Allergy Clin Immunol 2012; 129: 1588-1593.

54. Lin J, De A, Figueiredo L, et al. Pulmonary Alveolar Proteinosis in Association with Secondary Hemophagocytic Lymphohistiocytosis. J Pediatr 2017; 183: 191-195.

55. Cho K, Yamada M, Agematsu K, et al. Heterozygous Mutations in OAS1 Cause Infantile-Onset Pulmonary Alveolar Proteinosis with Hypogammaglobulinemia. $\mathrm{Am}$ J Hum Genet 2018; 102: 480-486.

56. Rawat A, Mathew B, Pandiarajan V, et al. Clinical and molecular features of $X$-linked hyper IgM syndrome - an experience from North India. Clin Immunol 2018; 195 59-56.

57. Gallagher J, Adams J, Hintermeyer M, et al. X-linked hyper IgM syndrome presenting as pulmonary alveolar proteinosis. J Clin Immunol 2016; 36: 564-570.

58. Vinh DC, Patel SY, Uzel G, et al. Autosomal dominant and sporadic monocytopenia with susceptibility to mycobacteria, fungi, papillomaviruses, and myelodysplasia. Blood 2010; 115: 1519-1529.

59. Tanaka-Kubota M, Shinozaki K, Miyamoto S, et al. Hematopoietic stem cell transplantation for pulmonary alveolar proteinosis associated with primary immunodeficiency disease. Int J Hematol 2018; 107: 610-614.

60. Inaba $\mathrm{H}$, Jenkins JJ, McCarville MB, et al. Pulmonary alveolar proteinosis in pediatric leukemia. Pediatr Blood Cancer 2008 51: 66-70

61. Cordonnier C, Fleury-Feith J, Escudier E, et al. Secondary alveolar proteinosis is a reversible cause of respiratory failure in leukemic patients. Am J Respir Crit Care Med 1994; 149: 788-794.

62. Dirksen U, Hattenhorst U, Schneider P, et al. Defective expression of granulocyte-macrophage colony-stimulating factor/interleukin-3/interleukin-5 receptor common beta chain in children with acute myeloid leukemia associated with respiratory failure. Blood 1998; 92: 1097-1103.

63. Ansari M, Rougemont AL, Le Deist F, et al. Secondary pulmonary alveolar proteinosis after unrelated cord blood hematopoietic cell transplantation. Pediatr Transplant 2012; 16: E146-E149.

64. Kajiume T, Yoshimi S, Nagita A, et al. A case of myelodysplastic syndrome complicated by pulmonary alveolar proteinosis with a high serum KL-6 level. Pediatr Hematol Oncol 1999; 16: 367-371.

65. Ranchod M, Bissel M. Pulmonary alveolar proteinosis and cytomegalovirus infection. Arch Pathol Lab Med 1979; 103 : 139-142.

66. Ito S, Wakahara K, Kojima T, et al. Two cases of autoimmune pulmonary alveolar proteinosis with rheumatoid arthritis. Allergol Int 2017; 66: 507-509.

67. Kimura $\mathrm{Y}$, Weiss JE, Haroldson KL, et al. Pulmonary hypertension and other potentially fatal pulmonary complications in systemic juvenile idiopathic arthritis. Arthritis Care Res (Hoboken) 2013; 65: 745-751.

68. Suzukl T, Trapnell BC. Pulmonary alveolar proteinosis syndrome. Clin Chest Med 2016; 37: 431-440.

69. Saper V, Deutsch G, Guillerman P, et al. Lung disease in systemic juvenile idiopathic arthritis (SIIA). Pediatr Pulmonol 2018; 16: Suppl. 2, 52

70. Schuler GS, Yasin Y, Carey B, et al. Systemic juvenile idiopathic arthritis-associated lung disease: characterization and risk factors. Arthritis Rheumatol 2019; 71: 1943-1954.

71. Samuels MP, Warner JO. Pulmonary alveolar lipoproteinosis complicating juvenile dermatomyositis. Thorax 1988; 43: 939-940.

72. Tanaka Y, Miyamoto T, Yoshitake S, et al. Rare combination of congenital heart disease and pulmonary alveolar proteinosis. Pediatr Int 2015; 57: 999-1001. 
73. Antoon JW, Hernandez ML, Roehrs PA, et al. Endogenous lipoid pneumonia preceding diagnosis of pulmonary alveolar proteinosis. Clin Respir J 2016; 10: 246-249.

74. Spagnolo $P$, Bush A. Interstitial lung disease in children younger than 2 years. Pediatrics 2016; 137: e20152725.

75. Vincent $M$, Karolak JA, Deutsch $G$, et al. Clinical, histopathological, and molecular diagnostics in lethal lung developmental disorders. Am J Respir Crit Care Med 2019; 200: 1093-1101.

76. Berteloot L, Taam RA, Emond-Gonsard S, et al. Primary pulmonary alveolar proteinosis: computed tomography features at diagnosis. Pediatr Radiol 2014; 44: 795-802.

77. Bush A, Anthony G, Barbato A, et al. Research in progress: put the orphanage out of business. Thorax 2013; 68: 971-973.

78. Bush A, Cunningham S, de Blic J, et al. European protocols for the diagnosis and initial treatment of interstitial lung disease in children. Thorax 2015; 70: 1078-1084.

79. Marangu D, Gray D, Vanker A, et al. Exogenous lipoid pneumonia in children: A systematic review. Paediatr Respir Rev 2020; 33: 45-51.

80. Gotts JE, Jordt S-E, McConnell R, et al. What are the respiratory effects of e-cigarettes? BMJ 2019; 366: 15275.

81. Dicpinigaitis PV, Trachuk P, Fakier F, et al. Vaping-associated acute respiratory failure due to acute lipoid pneumonia. Lung 2020; 198: 31-33.

82. Viswam D, Trotter S, Burge PS, et al. Respiratory failure caused by lipoid pneumonia from vaping e-cigarettes. BMJ Case Rep 2018; 2018: bcr-2018-224350.

83. Davidson K, Brancato A, Heetderks P, et al. Outbreak of electronic-cigarette-associated acute lipoid pneumonia North Carolina, July-August 2019. MMWR Morb Mortal Wkly Rep 2019; 68: 784-786.

84. Bush A, Bhatt J, Grigg J. E cigarettes: Tar Wars: The (Tobacco) Empire Strikes Back. Arch Dis Child 2019; 104: 1027-1039.

85. Choi HK, Park CM, Goo JM, et al. Pulmonary alveolar proteinosis versus exogenous lipoid pneumonia showing crazy-paving pattern: comparison of their clinical features and high-resolution CT findings. Acta Radiol 2010; 51: 407-412.

86. Fremond ML, Hadchouel A, Schweitzer C, et al. Successful haematopoietic stem cell transplantation in a case of pulmonary alveolar proteinosis due to GM-CSF receptor deficiency. Thorax 2018; 73: 590-592.

87. Reiter K, Schoen C, Griese M, et al. Whole-lung lavage in infants and children with pulmonary alveolar proteinosis. Paediatr Anaesth 2010; 20: 1118-1123.

88. Wilson CA, Arthurs OJ, Black AE, et al. Printed threedimensional airway model assists planning of singlelung ventilation in a small child. Br J Anaesth 2015; 115: 616-620.

89. Badiozaman R, Tahereh P, Shideh D, et al. Whole lung lavage of nine children with pulmonary alveolar proteinosis: experience in a tertiary lung center. Iran J Pediatr 2013; 23: 95-99.

90. Seymour JF, Presneill JJ. Pulmonary alveolar proteinosis: progress in the first 44 years. Am J Respir Crit Care Med 2002; 166: 215-235.

91. Ohnishi T, Yamada G, Shijubo N, et al. Secondary pulmonary alveolar proteinosis associated with myelodysplastic syndrome. Intern Med 2003; 42: 187-190.

92. Hammon WE, McCaffree DR, Cucchiara AJ. A comparison of manual to mechanical chest percussion for clearance of alveolar material in patients with pulmonary alveolar proteinosis (phospholipidosis). Chest 1993; 103: 1409-1412.

93. Trapnell BC, Nakata K, Bonella F, et al. Pulmonary alveolar proteinosis. Nat Rev Dis Primers 2019; 5: 16.
94. Seymour JF, Dunn AR, Vincent JM, et al. Efficacy of granulocyte-macrophage colony-stimulating factor in acquired alveolar proteinosis. N Engl J Med 1996; 335: 1924-1925.

95. Tazawa R, Trapnell BC, Inoue Y, et al. Inhaled granulocyte/ macrophage-colony stimulating factor as therapy for pulmonary alveolar proteinosis. Am J Respir Crit Care Med 2010; 181: 1345-1354.

96. Gajewska ME, Sritharan SS, Santoni-Rugiu E, et al. Autoimmune pulmonary alveolar proteinosis in an adolescent successfully treated with inhaled rhGMCSF (molgramostim). Respir Med Case Rep 2018; 23: 167-169.

97. Luisetti M, Rodi G, Perotti C, et al. Plasmapheresis for treatment of pulmonary alveolar proteinosis. Eur Respir J 2009; 33: 1220-1222.

98. Kavuru MS, Bonfield TL, Thomassen MJ. Plasmapheresis, GM-CSF, and alveolar proteinosis. Am J Respir Crit Care Med 2003; 167: 1036-1037.

99. Garber B, Albores J, Wang T, et al. A plasmapheresis protocol for refractory pulmonary alveolar proteinosis. Lung 2015; 193: 209-211.

100. Soyez B, Borie R, Menard C, et al. Rituximab for auto-immune alveolar proteinosis, a real life cohort study. Respir Res 2018; 19: 74.

101. Akasaka K, Tanaka T, Kitamura N, et al. Outcome of corticosteroid administration in autoimmune pulmonary alveolar proteinosis: a retrospective cohort study. BMC Pulm Med 2015; 15: 88.

102. McCarthy C, Lee E, Bridges JP, et al. Statin as a novel pharmacotherapy of pulmonary alveolar proteinosis. Nat Commun 2018; 9: 3127.

103. Suzuki T, Mayhew C, Sallese A, et al. Use of induced pluripotent stem cells to recapitulate pulmonary alveolar Proteinosis pathogenesis. Am J Respir Crit Care Med 2014; 189: 183-193.

104. Lachmann N, Happle C, Ackerman M, et al. Gene correction of human induced pluripotent stem cells repairs the cellular phenotype in pulmonary alveolar proteinosis. Am J Respir Crit Care Med 2014; 189: 167-182.

105. Happle C, Lachmann N, Skuljec J, et al. Pulmonary transplantation of macrophage progenitors as effective and long-lasting therapy for hereditary alveolar proteinosis. Sci Translat Med 2014; 250: 250ra113.

106. Lund-Palau H, Meng C, Pilou A, et al. Lentivirus GM-CSF gene therapy ameliorates autoimmune pulmonary alveolar proteinosis. Thorax 2018; 73: A1-A2.

107. Suzuki T, Arumugam P, Sakagami T, et al. Pulmonary macrophage transplantation therapy. Nature 2014; 514 : 450-454.

108. Takaki M, Tanaka T, Komohara Y, et al. Recurrence of pulmonary alveolar proteinosis after bilateral lung transplantation in a patient with a nonsense mutation in CSF2RB. Respir Med Case Rep 2016; 19: 89-93.

109. Nishinakamura R, Wiler R, Dirksen U, et al. The pulmonary alveolar proteinosis in granulocyte macrophage colonystimulating factor/interleukins $3 / 5$ beta c receptor-deficient mice is reversed by bone marrow transplantation. J Exp Med 1996; 183: 2657-2662.

110. Kleff V, Sorg UR, Bury C, et al. Gene therapy of $\beta$ (c)-deficient pulmonary alveolar proteinosis ( $\beta(c)$-PAP): studies in a murine in vivo model. Mol Ther 2008; 16: 757-764.

111. Cho K, Nakata K, Ariga T, et al. Successful treatment of congenital pulmonary alveolar proteinosis with intravenous immunoglobulin G administration. Respirology 2006; 11: Suppl., S74-S77.

112. Edwards C, Primhak R, Cohen MC. Pulmonary alveolar proteinosis associated with Epstein-Barr virus infection. Eur Respir J 2010; 36: 1214-1216. 